\title{
SOBRE EL CONSULADO CASTELLANO DE MALLORCA EN LA BAJA EDAD MEDIA
}

István Szászdi León-Borja

Universidad de Valladolid

El Consulado de los Castellanos en Mallorca se halla limitado por una escasísima y mal conocida documentación, ello ha sido la causa de que tan interesante institución haya sido abordada en contadas ocasiones hasta ahora. Nuestro objeto de investigación se centró primeramente en un importante documento cuyo registro se encuentra custodiado en el Archivo General de Simancas, el cual nos obligó a estudiar los documentos conocidos de este Consulado.

En 1964 se dieron a conocer algunos documentos referentes a los consulados castellanos en la Corona de Aragón. Aquéllos nos daban conocimiento de la temprana existencia de cónsules castellanos en Barcelona, Mallorca y Menorca, en el último año del siglo $\mathrm{XIV}^{(1)}$. Entonces supimos como el Cónsul de los Castellanos de Barcelona tuvo jurisdicción sobre todo el Principado de Cataluña, y que el de Menorca tenía también autoridad sobre los mercaderes castellanos de Ibiza. Hace pocos años se publicó el primer trabajo de investigación histórica que tuviera como tema el Consulado Castellano de Mallorca ${ }^{(2)}$. Era necesario articular buena parte de las interesantes noticias recogidas allí y en trabajos posteriores como en otras fuentes documentales sobre el particular desarrollo del Consulado "de la naçion de los castellanos de la çibdad e Reyno de Mallorcas".

\section{LOS CONSULES DE CASTELLANOS DE MALLORCA HASTA MEDIADOS DEL SIGLO XV}

La ciudad de Mallorca y su isla, contaron con un Cónsul de Castellanos ya antes de 1382, siendo el primero que conocemos Juan García de Guadalajara. Consulado de Castellanos que se componía de un Cónsul y sus procuradores y sustitutos. Sus competencias se vieron definidas al reconocerle el rey Pedro IV al cónsul Torrabadal las "causas et questiones que vertuntur seu verti sperantur in ipsa civitate inter castellanos quoscumque ad eandem declinantes seu ibi contrahentes ${ }^{\text {(3) }}$. 
Ya en 1399, el rey Martín de Aragón escribía al Rey de Castilla: "Ya sabedes como vos... nos dades los officios de consolado de los castellanos en algunas ciudades maritimas de nuestra senyoria... "(4). Muy pronto se manifestará una lucha y competencia entre los naturales del reino balear y los comerciantes castellanos por alcanzar el reconocimiento de la dicha dignidad. Si bien Pedro el Ceremonioso nombró al mercader mallorquín Joan Torrabadal en 1382, cesando a Juan García, la práctica corriente es que el dicho nombramiento fuese proveído por el Rey de Castilla. Siendo lo habitual que el Rey de Aragón recomendara un candidato, no siempre coincidente con la persona seleccionada para el dicho cargo. $Y$ que se limitara a confirmar la elección. Pero ni siquiera esto garantizó la estabilidad del consulado, las tensiones entre los naturales y los castellanos -andaluces, cántabros y vascos- ya eran evidentes en el cuarto final del siglo XIV. Así se demuestra por los sucesos que rodearon la elección del cónsul Nicolau Coha. Este había sido nombrado por Juan I de Castilla, en julio de 1385, pero no sin resistencia pues Juan García de Guadalajara reclamó haber confirmado su nombramiento. En 1397, Enrique III de Castilla nombró Cónsul de Castellanos en Mallorca al sevillano Pedro González de Palacios, quien le confirmó en el cargo el 31 de octubre de 1399. El rey Martín de Aragón le reconoció y confirmó el 6 de octubre de 1400 , pero a pesar de ello tuvo que litigar con Juan Olivella quien había sido nombrado Cónsul de Castellanos en Mallorca el año de 1396. Otro ejemplo de los conflictos que rodeaban la elección del cónsul es el del nombramiento del santanderino avecindado en la ciudad de "Mallorcas" Rodrigo González de Lago, quien nombrado por el rey Juan II de Castilla en 1426 y confirmado en 1427 por Alfonso $V$ de Aragón, tuvo que defender su cargo ante Juan Olivella quien alegaba su pasado nombramiento. González de Lago logró prevalecer como Cónsul de Castellanos ${ }^{(5)}$.

Quizás uno de los factores interesantes en el estudio de los Cónsules de Castellanos, en Mallorca, naturales de la Corona de Aragón es su especial vinculación con los reyes aragoneses, tendencia que en el futuro será casi una exigencia. Cuando en 1382 Pedro IV de Aragón destituyó al cónsul García de Guadalajara, nombró a Joan Torrabadal en su lugar, quien desde 1356 era "domesticum et familiarem nostrum" según el mismo rey. El Cónsul Juan Olivella era maestro ballestero y en 1417 fue nombrado por el rey Alfonso $V$ "hortelano" del castillo de la Almudaina, la morada regia de la ciudad de Mallorca. Otro tanto ocurrirá con Gonçalvo d'Avila, quien en 1399 fue recomendado por el rey Martín el Humano al Rey de Castilla para que le proveyese con algún oficio consular de los castellanos en los reinos de Aragón, por ser persona vinculada a su corte $^{(6)}$. Incluso causa la sensación que el Rey de Aragón intercedía indirectamente ante el Rey de Castilla para favorecer el nombramiento de vasallos allegados, mayormente oficiales y servidores de la corte, de quien tenía plena confianza y comunicación. Otro claro ejemplo de lo dicho es el del halconero de Alfonso V, Pedro Serra, natural de Segorbe, quien su 
señor le nombró Cónsul General de Castellanos en 1445. O el nombramiento por el mismo rey a favor de Joan Margarit, Baile de Alicante y perteneciente a un ilustre linaje de servidores reales, como Cónsul General $^{(7)}$. Ante esta tendencia se alzaron los mercaderes castellanos y vascos quienes intentarían frenarla, proponiendo su propio candidato al Consulado.

\section{LOS MAREANTES PORTUGUESES Y EL CONSULADO CASTELLANO DE MALLORCA}

Desde el 13 de noviembre de 1419 ocupó el oficio consular Luis Rodiu, quien era natural de Castilla y vecino de Mallorca; éste representó a castellanos y a portugueses hasta su muerte en 1434. Entonces los mercaderes y mareantes portugueses y castellanos impugnaron al cónsul interino por defecto de forma, reclamando que al morir el Cónsul "segons comú us e pratiqua de totes les terres mercantivols del universal món, lo president de la dita terra, appellats e convocats los hòmens de la dita nació, ab voler e expres consetiment lur, proveex del dit offici de persona idonea e sufficient, tro e tant que per lur senyor natural o communitat hi és en altre manera provehit". Proponiendo a Pero Net, mercader mallorquín, para el oficio consular por ser "notable e hu dels hòmens singulars en lo present regne". Pero al año siguiente Juan II de Castilla sancionó, y Alfonso $V$ de Aragón confirmó, al cónsul interino Bartolomé Palau que había sido nombrado por el Lugarteniente de Mallorca al quedar vacante el cargo. El nuevo cónsul, Bartolomé Palau (Palacio ?), era natural de Castilla, como le reconocía Juan II, aunque avecindado en la Ciudad de Mallorcas. El Rey de Aragón le consideraba como "bona, ydonea e sufficient persona". Posiblemente fuera pariente del cónsul Pedro González de Palacios nombrado por el Rey de Castilla en 1397.

El hecho que castellanos y portugueses reconocían por su cónsul al Cónsul de Castellanos de Mallorca, puede indicar que ésa realidad fuera anterior al mismo año de 1434 , en que tenemos noticia de ello, pero también es cierto que durante aquel período las relaciones entre Castilla y Portugal fueron fluidas y buenas, lo que llevaría en el exterior a situaciones de colaboración. Más tarde, en 1471, el que tres años antes figuraba como Vicecónsul de los Castellanos en Mallorca, el comerciante maliorquín Joan Arnau, era el Cónsul de Portugal en la isla balear ${ }^{(8)}$. Lo que indica el grado de amistosa cooperación entre ambas comunidades y su integración en el medio mercantil mallorquín. De Arnau se conserva un salvoconducto a su favor otorgado en Barcelona el 13 de agosto de 1464 por don Pedro de Portugal, durante su reinado en Cataluña ${ }^{(9)}$. Según parece éste había sido preso y luego puesto en libertad con licencia de poder regresar a su casa. El dicho salvoconducto iba dirigido a los capitanes, patrones, subpatrones, cómitres, subcómitres y marineros de cualquier navío bajo la bandera del "Soberano". Es de creer que don Pedro tenía a Arnau por uno de los 
suyos, lo que llevaria a la amistad con la comunidad portuguesa de su ciudad. Durante el gobierno del condestable don Pedro de Portugal, se había favorecido a los comerciantes portugueses, que ordinariamente eran proveedores de pescado, en Cataluña. Ello favoreció el acrentamiento de su número e importancia en otras partes como Valencia donde castellanos y portugueses hicieron "naçión" ${ }^{1(10)}$. Lo mismo ocurrió en Mallorca, como hemos descrito. Volviendo a Arnau, valga añadir que, en septiembre de 1468, Enrique IV de Castilla, le repuso en su antiguo oficio en Mallorca de forma vitalicia aunque le cesó dos años después. Cuando el rey Enrique nombró a Joan Arnau le hizo cargo de "qualesquier pleydos e causas, asy civiles como criminales, que entre los nostros subditos e naturales son acaescidos e acaescieren en la ditcha ciutad e ysla"(11). Desde septiembre de 1465, hasta su muerte en 1468, ocupó el Consulado de Mallorca y de Ibiza, un vecino de esta última isla y natural de Santander, Pedro García de Calleja. En 1470 era Cónsul de Castellanos en Mallorca Rodrigo González, a quien se le reconoció el derecho a cobrar el $1 \%$ de la mercadería de "tot mercader castella o portagales o altre generacio d'Espanya" ${ }^{(12)}$. Cuando se escribía que "es tengut de procurar e defensar a toda generacio D'Espanya" se incluía, como es bien sabido a los naturales del reino de Portugal ${ }^{(13)}$. Y esta situación de comunidad tanto en derechos como en obligaciones bajo la sombra de un mismo cónsul debió ser la existente en Mallorca hasta la Guerra de Sucesión Castellana. Por la cual el rey Alfonso $V$ de Portugal se enfrentó a los partidarios de la Infanta doña Ysabel de Castilla y de su marido Fernando de Aragón, los Príncipes de Sicilia, entre 1475-1479, en defensa de la hija de Enrique IV. Juan II de Aragón, había hecho todo lo posible para evitar la guerra entre el Rey de Portugal y sus hijos. Don Juan había tratado hasta el final de mantener al Arzobispo de Toledo en el partido de su nuera y había intentado mantener la paz entre ésta y "el Africano". El 10 de abril de 1475, el Rey de Aragón le ofreció a Dom Afonso como garantías de buena voluntad auxilio para una empresa contra el Reino de Tremecén que preparaba el monarca lusitano, y el levantamiento de unos tributos que gravaban el comercio portugués con Valencia. Parecía que soplarían buenos vientos para los comerciantes y mareantes portugueses en sus negocios en Levante. Pero, la crisis política castellana estropeó esas perspectivas de colaboración luso-aragonesas en el Mediterráneo. El 11 y el 28 de mayo don Fernando escribió a su augusto padre pidiéndoles casi con desesperación que declarase la guerra al Rey de Portugal y que atacara desde Valencia el señorío de Villena. Para empeorar el clima entre Aragón y Portugal, el 23 de septiembre de 1475 se celebró en París la firma de un tratado entre Luis XI y Alfonso $V$, que precedía otro de mutuo apoyo acordado en Senlis por las mismas partes por el cual se consideraba el reparto de la Corona de Aragón entre los aliados. El condado del Rosellón y el Reino de Mallorca pasarían a pertenecer al rey Luis, mientras Aragón y Valencia se convertirían en reinos del Rey de Portugal ${ }^{(14)}$. La vida de los subditos de Alfonso $\mathrm{V}$ en los puertos de Aragón no debió ser fácil ni cómoda. En 
septiembre de 1476 el rey Alfonso $V$ de Portugal navegaba frente a las costas de Cataluña camino de la corte francesa donde esperaba encontrar el apoyo necesario en Luis XI. El 3 de mayo, en Madrigal, se habían firmado los capítulos matrimoniales de la Princesa de Asturias y el Príncipe de Cápua, por parte napolitana además de 50.000 ducados en arras, y otras cosas, se ofrecía armar durante seis meses doce galeras para servir a los Reyes de Castilla en aguas de Francia, Castilla y Portugal. Aquello pretendía ser un verdadero Pacto de Familia aragonés que afectó al Mediterráneo como al Atlántico ${ }^{(15)}$. En enero de 1479 moría Juan II y heredaba el trono don Fernando, Castilla y Aragón tenían reyes comunes, y la unión personal de reinos ofrecería mayores beneficios al trato mercantil y prosperoidad de los vasallos. Aquel año, también, fue el de la paz entre Castilla y Portugal por el Tratado de las Alcaçovas.

\section{EL CONSUlado DE CASTELLANOS BAJO LOS REYES CATOLICOS}

A comienzos de la década de 1460 era Cónsul General de Castellanos, Bartolomé de Melgar, cuyo oficio su hijo y homónimo revalidó en 1469. Era por 1470 su vicecónsul en Mallorca Rodrigo González ${ }^{(16)}$. Seis años más tarde, Melgar tuvo que pleitear para defender sus derechos cuando, "a propuesta" de los concejos vascos y cántabros, Ysabel y Fernando otorgaron el Consulado de Castellanos de Mallorca a Martín de Portugalete, proveyendo el darle posesión en el cargo ${ }^{(17)}$. Bartolomé de Melgar alegó que los Reyes habían otorgado la dicha Carta de Merçed a favor de Martín de Portogalete "con rrelaçion no verdadera", exponiendo como el Rey don Enrique había hecho merced a su padre del "ofiçio de Consulado de todos los nuestros Reynos e señorios de Aragon e Seçilia con facultad que lo pudiese rrenunçiar en qualquier persona quel quisiese... e que despues rrenunçió el dicho ofiçio en el... su fijo e fue confirmada la dicha rrenunçiaçión que del fue fecha por el señor Rey don Enrrique e le fue fecha nueva merçed del dicho ofiçio de Consulado al dicho Bartolomé de Melgar... " Además, después que doña Ysabel y don Fernando sucedieron en el trono de sus reinos, confirmaron la dicha merçed a Melgar y le dieron facultad para que la pudiese renunçiar en un hijo suyo cuando quisiese por virtud de "las dichas merçedes e confirmaçiones". Debió ser el mismo Bartolomé de Melgar, hijo, quien alegó la ley de las Cortes de Toledo, sobre renunciación de los oficios públicos, señalando que no habia incurrido en su incumplimiento. A lo que los Reyes ordenaron que fuera reconocido como su "Cónsul de los mercaderes e otras personas destos nuestros Reynos de Castilla e de León en la dicha çibdad e Reyno de Mallorcas" ${ }^{1(18)}$. Bartolomé de Melgar se vería obligado a impugnar la elección de Bartomeu de Cunilleres, alias de Pachs, cuando un grupo de patrones vascos destituyeron al vicecónsul Gabriel Vidal debido a su absentismo y le eligieron para el oficio ${ }^{(19)}$. Pachs 
pertenecía a la aristocracia de Mallorca y gozaba de buenos amigos en la Corte, ello explica porqué se resolvió el proceso tres años después. Melgar fue repuesto en el Consulado en 1491 pues claramente se hubiera obrado contra derecho de proceder lo contrario. Mas hay indicios suficientes para creer que el apoyo que recibió Pachs provenía de los mismos Reyes quienes buscaban reorganizar el sistema consular tratando de centralizarlo en manos de personas de toda confianza y crédito, además de reformar el estado de cosas obra de Enrique IV. Personas que fueran respetadas y que no delegaran en terceros sus responsabilidades derivadas del oficio, para poner fin al estado de cosas que formaba parte del desgobierno de Enrique IV. Bartolomé de Pachs, vecino de Mallorca, debía de ser una de esas personas puesto que el 3 de marzo de 1490, el Rey don Fernando confirmaba el nombramiento hecho a su favor por el Rey de Nápoles para el oficio de Cónsul General de sus vasallos en la Ciudad y Reino de Mallorca ${ }^{(20)}$. Seis años después el Rey Católico intercedió ante el Rey de Nápoles para que se hiciera justicia a "mossen Barthomeu de Pachs, vezino de Mallorcas" por el incumplimiento de Joan Vidal, que se encontraba en el reino napolitano, de una seguridad al que estaba obligado por un contrato. Entonces don Fernando dice de Barthomeu de Pachs que "el dicho mossen Pachs es persona que nos ha mucho seruido". Nótese que no se menciona su coficio consular, lo que indica que por entonces ya no lo era, por 1501 el rey Fernando volvía a intervenir por Pachs ante el Rey de Nápoles para que se hiciera justicia en el dicho pleito de $1496^{(21)}$. Entonces el Rey de Aragón hizo referencia de Pachs como "cauallero del nuestro reyno de Mallorques". Por sus muchos y buenos servicios al Rey, quien debió tener responsabilidad en su elección, "Bartholomeus de Conilleres, alias de Pache" fue nombrado Cónsul de Niza y de los súbditos del Duque de Saboya en la Ciudad y Reino de Mallorca con fecha de 5 de julio de 1501 por el duque Filiberto y fue confirmado por el rey Fernando en Toledo a 27 de junio de 1502. Pero poco le duró el oficio de Cónsul de Nizardos pues el 10 de marzo de 1503, don Fernando proveía que Luis Burgarelli, que residía en la Ciudad de Mallorca, fuera repuesto en el Consulado de Niza y de los súbditos del Duque de Saboya, haciendo revocación del nombramiento a favor de Bartolomé de Pachs. Burgarelli había alegado su nombramiento por la Duquesa de Saboya, Blanca, el 14 de de octubre de 1495; como la confirmación del duque Filiberto del 8 de marzo de 1501 y la Real Provisión fecha en Granada el 27 de junio del mismo año ${ }^{(22)}$. Que tales provisiones, mercedes y honores sobre Bartolomé de Pachs tenían su origen en la protección real y en la confianza que su linaje serviría fielmente al Rey, lo demuestran los nombramientos de deudos próximos suyos por la misma época ${ }^{(23)}$. Tenemos noticias de tres miembros de la familia mallorquina "de Pachs": Nicolás, su hijo Arnaldo y su nieto Bonifacio - hijo del anterior. Un revelador documento del 20 de abril de 1491, fechado en Alcalá la Real, por el cual el Rey se dirigía al Dux de Venecia, Agostino Barbarigo, recomendándole a Bonifacio para que le 
concediera el oficio de Cónsul de Venecianos en Mallorca, nos explica la consideración de don Fernando con los Pachs: "Bonifacio de Pachs, mallorquín, ha tenido mucho tiempo el consolado de venecianos en la nuestra ciudat y reyno de Mallorcas, y su padre y agüelo touieron el dicho officio; y dizese que se houieron con mucha integridat y bondat en el regimiento del, y specialmente el dicho Bonifacio. $E$ porque hauemos sabido que, el que agora postreramente tenia el dicho consolado, es fallecido, y por ser el dicho Bonifacio persona assi abil e sufficiente para regirlo, querriamos fuesse conferido a el, por ende vos rogamos, quanto affectuosamente podemos, que, por amor y complacencia nuestra vos plega proueer del dicho officio de consolado al dicho Bonifacio de Pachs" (24). Bartolomé y Bonifacio eran contemporáneos y posiblemente hermanos, intentando así conseguir su familia el controlar los consulados de extranjeros que existían en el Reino de Mallorca con la aprobación del Rey.

La escasa documentación existente en torno al Consulado de Castellanos de Mallorca ha hecho creer que era "improbable" la existencia de un archivo consular, poniéndose en duda la propia existencia de una administración interna. Todo ello es producto de la desaparición del Archivo del Consulado, del cual esperemos haya subsistido algún fondo todavía oculto y por tanto extraviado a la investigación. Conocemos el hecho que a finales del siglo XIV el notario Pedro Tordera custodiaba los libros del Consulado de Castellanos de Mallorca ${ }^{(25)}$. También conocemos que cuando el nuevo Cónsul recibía su Provisión de nombramiento, en persona o por procurador o el Vicecónsul la presentaba ante el Gobernador o Lugarteniente de Mallorca para su toma de posesión. Entonces juraba su cargo sobre los Evangelios y se pregonaba por la ciudad su nombramiento, otras veces el nuevo Cónsul, acompañado por un notario de la Gobernación y por un Macero, se dirigian al Consulado del Mar para dar conocimiento de la toma de posesión del oficio, siguiendo el presentarse en la escribanía del Notario en cuyo poder obraban los protocolos consulares, dando testimonio de su incorporación, y recibiendo el sello del Consulado ${ }^{(26)}$.

\section{LA EXPERIENCIA CONSULAR CASTELLANA MEDITERRANEA}

En Mallorca el intento de la unión de los consulados extranjeros fracasó, la evidencia histórica hace creer que hubo ese proyecto y que el propio Rey Católico fuera quien lo ideó. Los tímidos intentos chocaron contra las propias comunidades nacionales de mercaderes y mareantes extranjeros como contra los privilegios de éstas. La intervención oculta del Rey se vio frenada por las instituciones tradicionales que él había reconocido. Ello resulta evidente cuando nos aproximamos a la vida consular de otras ciudades de la época. El caso de Málaga, por ser ciudad castellana, y donde el Rey tenía mayor libertad de intervención en la vida 
local es donde lo anteriormente expresado resulta patente. En 1490 se instituyó el Consulado de Catalanes de Málaga, a cuya cabeza había un Cónsul nombrado por los Consellers de Barcelona. La primera reacción del Concejo de Málaga fue negarse a recibirlo, y por tanto, impidiendo la toma de posesión del oficio. El Concejo malagueño pidió a los Reyes que proveyeran un Cónsul General del Puerto, oficio hasta entonces inexistente. Así el 28 de marzo de 1491, los Reyes hicieron merced a Alonso Charino, vecino y Regidor de Málaga, del Consulado del puerto de esa ciudad "de todas las naçiones destranjeros que de fuera destos nuestros reynos e señorios de Castilla a la dicha çibdad vinieren ansy por mar como por tierra... "Tal medida beneficiaba tanto al regimiento malagueño, por permitir el control del tráfico comercial extranjero, del abastecimiento de la ciudad y del movimiento de los comerciantes en el puerto -pues como hemos dicho, Cherino era Regidor-; como a los mismos Reyes en el afán de controlar todas las jurisdicciones del reino. Según los Reyes, el Cónsul General de Málaga tendría por competencias "segun que fazen e acostunbran fazer los otros nuestros consules estantes en los otros puertos de los dichos nuestros reynos e señorios". El Consulado General, el Concejo de Málaga alegaba que su "ofiçio es syn perjuysio alguno procurar por los estranjeros que a esa dicha çibdad vienen syn juridiçion alguna". Finalmente los Reyes se vieron obligados a ordenar al Concejo malagueño el recibir al Cónsul de Catalanes, las autoridades barcelonesas habian conseguido el reconocimiento de sus privilegios. Ello con una serie de condiciones muy expresivas de cuáles eran las preocupaciones de los Reyes: el Cónsul tendría competencia en materia civil siempre y cuando ambas partes fueran catalanes, en caso contrario sería el Corregidor la autoridad judicial; luego, las sentencias del Cónsul sólo eran apelables ante el Corregidor de Málaga, cuyas sentencias serian firmes. El Corregidor debía dictar sentencia tomando "consigo dos mercaderes catalanes los que a el mejor paresçiere para que con su consejo lo determinen". Considero que no le falta razón a Ruíz Povedano cuando reconoce en este hecho un precedente evidente a la política real de regulación del sistema de apelaciones llevada a cabo un año después para el Consulado de Burgos ${ }^{(27)}$. Los comerciantes de Burgos habían hecho súplica a los Reyes para que en materia de apelación de las sentencias consulares fuera según el uso de Barcelona y de Valencia, es decir, ante dos mercaderes "sacados e nonbrados para oyr apelaciones ${ }^{(28)}$. Los Reyes legislaron, en cambio, según la Pragmática Real, de 21 de julio de 1494, por la cual se concedió jurisdicción al Consulado burgalés que: "mandamos que de la sentencia, o sentencias que assi dieren los dichos prior e consules entre las dichas partes, si alguna dellas apelare, que lo pueda fazer ante nuestro corregidor que agora es, o fuere dela dicha cibdad de Burgos, e non para otra parte. Al qual dicho corregidor mandamos que conozca dela dicha apelacion: e para della conoscer e la determinar tome consigo dos mercaderes dela dicha cibdad los que a el paresciere que son hombres de buenas consciencias: 
los quales fagan juramento de se auer bien e fielmente enel negocio que ouieren de entender, guardando la justicia a las partes: e conosciendo e determinando la dycha causa por estilo delos mercaderes, sin libelos ni escritos de abogados: saluo solamente la verdad sabida e la buena fe guardada como entre mercaderes: sin dar a luengas de malicias ni a plazo ni a dilaciones de abogados. E si los dichos corregidor e dos mercaderes confirmaren la dicha sentencia que assi fuere dada por los dichos prior e consules, mandamos que della no aya mas apelacion ni agrauio ni otro recurso alguno: saluo que se ejecute realmente e con efeto... "(29). El mismo orden de apelación que se quiso implantar en Málaga. En realidad aquí se manifiesta una de las mayores preocupaciones de los Reyes en el orden de la administración de la justicia, que ésta fuera breve en sus causas y acabar con las malicias y dilaciones de los abogados, que consta tan temprano como en 1480 en el Ordenamiento de las Cortes de Toledo ${ }^{(30)}$. Sus Altezas buscaban librar a la justicia de vicios que entorpecían su marcha, y muy en especial cuando la materia era la comercial. La intervención de los corregidores constituía desde esta perspectiva una garantía para los comerciantes y mareantes de la buena y eficiente administración de la justicia, la Ley 46 del Ordenamiento de las Cortes de Toledo así lo demuestra claramente ${ }^{(31)}$.

Una diferencia, entre el proyectado Consulado General del Puerto de Málaga y el Consulado de Burgos, según la Pragmática Real de 1494, era el que mientras en el primero su privilegio era otorgado a la ciudad, en el segundo éste era otorgado a la Universidad de los mercaderes de la ciudad de Burgos. En la Corona de Aragón sólo se había otorgado carta de privilegio a una cofradía de mercaderes en el caso de Barcelona en 1258. Entonces la "Universitas proborum hominum riparie civitatis Barchinone" recibió la "Carta consulatus maris riparie Barchinone". En los casos posteriores los privilegios se habían otorgado a las ciudades y villas o a los propios consulados ${ }^{(32)}$. Lo que indica el prestigio que ya tenía la Universidad de los mercaderes de Burgos, y la voluntad de los Reyes de facilitar el desarrollo de juicios breves. Pero en realidad aquí lo subrayable es que tal privilegio fundacional se otorgó a la corporación de mercaderes, tal como se hizo en Aragón con el Consulado de Castellanos de Mallorca.

El triunfo de los catalanes en conseguir de los Reyes el reconocimiento de su Consulado en Málaga, en enero de 1495 tuvo como inmediata consecuencia el fracaso del Concejo malagueño en su intento de controlar las "naciones" que traficaban y vivían en la ciudad. Al poco tiempo genoveses, nizardos y franceses conseguirían sus propios consulados en aquel puerto andaluz ${ }^{(33)}$. Mas las autorides reales consiguieron limitar el poder consular, como hemos visto, aunque de una manera más limitada al plan original. La experiencia fallida de Mallorca, en esa misma línea de unificación de los consulados de extranjeros, y con las mayores dificultades que ofrecían los privilegios en Aragón y el particular derecho mallorquín, no puede ser despreciada a la hora de valorar la dicha política de intervención real en la vida consular. A partir de 1494, la 
Corona utilizará al Consulado como la eficaz institución que permita esa meta -de intervención-, ya no haría falta el enfrentar a las autoridades locales con los mercaderes.

No podemos conocer el grado de aprovechamiento de la experiencia consular castellana en Mallorca, sin poder conocer su régimen interno. Posiblemente tuviera el Consulado unos capítulos u ordenanzas particulares como ocurrió con otros consulados castellanos o españoles en el Mediterráneo contemporáneamente ${ }^{(34)}$. El tráfico intenso entre el Golfo de Vizcaya y el Mediterráneo hacían que vascos y castellanos de las Cuatro Villas estuvieran familiarizados con los puertos a orillas del "Mare Nostrum". En Valencia, los castellanos pidieron un consulado propio y en 1400 los valencianos negaron tal derecho basándose en que tenían privilegio de gozar de dos cónsules de mar, y que además de estar ocupados los oficios no aceptarían a un extranjero. Hay que esperar hasta 1477 para que tengamos noticia que los Reyes proveyeran el oficio de Cónsul de Castellanos en Valencia en la persona de Pedro del Castillo, vecino de Villena. La misma provisión indica que se proveyó nuevo cónsul porque el oficio estaba vacante, por lo cual el inicio de ese Consulado era anterior a esa fecha. No se conoce documentación de inicios del siglo siguiente que permita creer su supervivencia institucional, pero en cambio sí consta que en 1504 los patrones y mercaderes vascos eligieron Cónsul de Vizcaínos y Guipuzcoanos en Valencia a Pedro de Vidania, mercader de Azcoitia ${ }^{(35)}$. Patrones vascos en Mallorca alegaron en 1488 un privilegio real por el cual: "tribuitur familias hominibus naciones regni Castelle, quod quotienscumque contingerit adesse in uno portus quinque naves, patroni illarum concordes, si eis videtur, possunt destituere et revocare consulem sue nacionis illius loci et alium eligere." Al Rey no le constaba tal privilegio pero pidió a su Lugarteniente en Mallorca que se informara. Tanto Martín de Portugalete, como Bartolomé de Pachs, habían sido apoyados por los vascos para alcanzar el Consulado de Castellanos en Mallorca ${ }^{(36)}$. Y quiero subrayar ese protagonismo de los patrones vizcaínos y guipuzcoanos, como también cántabros, para evidenciar la intensa relación entre los hombres de mar del Cantábrico y del Mediterráneo, Si Fuenterrabía y Colliure estaban separados por tierra, sus hombres se encontraban unidos por el mar, podríamos decir usando lenguaje metafórico. Ello permitió el conocimiento de sus instituciones corporativas mercantiles desde hacía tiempo. Los consulados castellanos de Valencia y de Mallorca tenían muy cerca a la vista al Consulado del Mar valenciano, siendo testigos del éxito del "Orden judicial de Valencia" que era el observado en los tribunales consulares de Barcelona, Mallorca y Perpiñán. Los Cónsules de Valencia juzgaban de acuerdo con el uso o costumbre del mar de manera breve y sumaria $^{(37)}$. Y el Consulado de Burgos, refleja ese respeto y admiración hacia los Consulados del Mar, especialmente el de Valencia ${ }^{(38)}$. El regidor burgalés Diego de Soria, en nombre del prior y cónsules de la Universidad, elevó a los Reyes la petición que presentó ante el Consejo, diciendo: "que bien sabiamos como en las cibdades de Valencia y Barcelona e otras 
partes de nuestros reynos donde auia copia de mercaderes, tenian consulado e autoridad para entender en las cosas e diferencias que tocaua a la mercaderia, es assaber en conpras e ventas y en canbios y en seguros y en diferencias de cuentas delos amos e sus fatores, e de vn mercader a otro y en conpañias que ouieren tenido e touiessen en afletamiento de naos, e para las diferencias que acaescieren entre los mercaderes e sus fatores que ouiessen estado fuera del reyno con las fatorias... assi en las diferencias mouidas por pleytos ante juezes ordinarios como las que estauan por mouer: porque sabiamos que los pleytos que se mouian entre mercaderes de semejantes cosas como las suso dichas nunca se concluyan ni fenescian, porque se presentauan escritos e libelos de letrados de manera que por mal pleyto que fuese, le sostenian los letrados de manera que los fazian ynmortales" ${ }^{\prime \prime}(39)$.

Los Reyes, desde inicios de su reinado, habían seguido una política de deshacer entuertos en el orden económico que afectaren a sus vasallos como al bienestar global de sus reinos y señoríos. Su preocupación en las Cortes de Toledo de 1480, y a petición de los procuradores, por facilitar el comercio entre los reinos de Castilla y la Corona de Aragón evidencian una sensibilidad dirigida a hallar nuevas soluciones a problemas seculares tal como vimos que ocurrrió en 1494 con la Universidad de mercaderes de Burgos. La Ley 111 del Ordenamiento de las Cortes de Toledo de 1480 proclamaba: "Pues por la gracia de Dios, los nuestros reynos de Castilla e de Leon e de Aragon son unidos, e tenemos esperanza que por su piedad de aqui en adelante estaran en union e permanesceran en nuestra corona real, que ansi es razon que todos los naturales dellos se traten e comuniquen en sus tratos - e. fazimientos, por ende a peticion de los dichos procuradores, ordenamos e mandamos que todos los nuestros mantenimientos e bestias e ganados e otras mercaderias de qual quier qualidad que sean, que fasta aqui eran vedadas por las leyes e ordenanzas destos nuestros reynos de Aragon, que de aqui adelante todas se puedan pasar e pasen libre e seguramente a los dichos reynos de Aragon, sin pena ni calunia alguna e sin enbargo de uedamiento dellas, fecho por las dichas leyes e ordenanzas, con tanto, que siempre las tales cosas sean e finquen diezmeras para nos e nuestros succesores, e se pague el diezmo e se escriua en las aduanas, segun se acostumbró en los tiempos pasados fasta aquí de las cosas uedadas... ${ }^{(40) " \text { ". }}$

Este era el espíritu tanto de los Reyes como de sus vasallos a ambos lados de la frontera de Castilla y de Aragón. Al constituirse el Consulado burgalés, como fundamenta la Pragmática, se reconoció como modelo precedente los consulados de Barcelona y Valencia. Tampoco se pueden despreciar los humildes consulados de castellanos de la Corona aragonesa, quienes sirvieron como un primer experimento consular para los vasallos de la reina Ysabel. Todo ello sirvió, experiencia y práctica de los castellanos en la contratación mercantil mediterránea. Recordemos que el contenido jurídico que tiene la Pragmática fundacional del 
Consulado de Burgos en 1494, será el patrón del de los consulados de Castilla e Yndias posteriores, por tanto podemos atribuirle el punto de partida del ordenamiento comercial castellano en la Edad Moderna ${ }^{(41)}$. ¿Qué mayor aprovechamiento se podía hacer de lo aprendido por mareantes y mercaderes fuera de Castilla? 


\section{NOTAS}

1. FERRER I MALLOL, MARIA TERESA: Documents sobre el consolat de castellans a Catalunya i Balears. Anuario de Estudios Medievales. Instituto de Historia Medieval de España. Barcelona, 1964. pp. 599-605.

2. CATEURA BENNASSER, PABLO: El consulado medieval de Castilla en el Reino de Mallorca. Actas del II Congreso de Historia de Andalucía. Historia Medieval II. Publicaciones de la Consejería de Cultura y Medio Ambiente de la Junta de Andalucía, Córdoba. 1994.

3. Ibídem, pp. 296-297. Respecto de los delegados y sustitutos del Cónsul éstos fueron frecuentes. El sevillano González de Palacios al nombrársele Cónsul, a su vez reconoció a Gonzalo Fernández -vecino de Sevilla y cómitre- quien nombró a Martín Dordas -vecino de Mallorca- como procurador sustituto para poder tomar posesión en su nombre el año de 1397.

4. FERREIRA PRIEGUE, ELISA: Cónsules de castellanos y cónsules de españoles en el Mediterráneo bajomedieval. Castilla y Europa. Comercio y mercadurías en los siglos XIV, XV Y XVI. Diputación Provincial de Burgos, 1995. p. 199.

5. FERRER I MALLOL (1). Caso único es el de Gozález de Lago quien alegó que el Almirante de Castilla le había otorgado el oficio vitaliciamente en 1419. CATEURA (2), p. 297.

6. Ibídem.

7. CATEURA (2), pp. 294, 297. Estos Cónsules Generales aparecen a partir de la tercera década del siglo XV, radicando en Barcelona desde donde tenían jurisdicción territorial de toda la Corona. A la vez subsistían Cónsules de Castellanos particulares en Mallorca y en Menorca con conflictos de jurisdicciones. Margarit a su vez nombró Pere Safortesa como su procurador en Mallorca quien a su vez nombró Cónsul Sustituto al notario Jordi Bagó. Para referencias de los servicios prestados por los Margarit a los Trastamara de Aragón, cosúltese el libro de Miguel Batllori: Humanismo y Renacimiento. Ariel, Barcelona, 1987. p. 94. Sobre el contino Pedro Margarit, véase mi artículo: Guatiao, los primeros tratados de Indias. Actas del IX Congreso del Instituto Internacional de Historia del Derecho Indiano. Editorial Complutense, Madrid. 1991. T.I. pp. 414-415.

8. CATEURA (2), pp. 295-297.

9. MARTINEZ FERRANDO, J. ERNESTO: Catálogo de la documentación de la Cancillería Regia de Pedro de Portugal. Servicio de publicaciones del Ministerio de Educación Nacional. Madrid, 1953. p. 152.

10. FERREIRA PRIEGUE, ELISA: El comercio Galicia-Valencia en la segunda mitad del siglo $X V$. Lluis de Santangel i el seu temps. Ayuntamiento de Valencia, 1992. p.348.

11. CATEURA (2), pp. 296-298.

12. FERREIRA (4), pp. 207-208. 
13. Sobre la voz "España" a fines del siglo XV, véase el libro de ISTVAN SZASZDI LEON-BORJA Y KATALIN KLIMES-SZMIK: El Memorial Portugués de 1494. Una alternativa al Tratado de Tordesillas. Ministerio de Cultura - Testimonio Compañía Editorial, Madrid. 1994. p. 133.

14. VICENS VIVES, J.: Monarquía y revolución en la España del siglo XV. Juan I/ de Aragón. Editorial Teide, Barcelona, 1953. p. 358.

15. Ibídem. p. 361.

16. CATEURA (2), p. 298.

17. Ver el apéndice documental.

18. La ley 62 del Ordenamiento de las Cortes de Toledo de 1480, dice: Muchos fraudes se facen en la renunciacion de los oficios publicos, e quando algun ome que tiene oficio publico se ve cercano a la muerte e que non lo puede tener por sy, entonces lo renuncia e otros procuran con el que faga la renunciacion, e esto tiende en perjuyzio de nuestra real preheminencia e en algun danno dela republica, por ende, ordenamos e mandamos que de aqui adelante la renunciacion que alguno fiziere de su oficio que touiere, non vala, saluo sy biniere veynte dias despues que otorgare la tal renunciacion, e de otra guisa, que nos podamos proueer del dicho oficio, sin enbargo dela tal renunciacion e dela prouision que por virtud de ella se diere, asy como prouyeramos sy nunca la tal renunciacion interuiniera. [Cortes de los Antiguos Reinos de León y de Castilla. Publicadas por la Real Academia de la Historia. T. IV. Madrid, 1882. pp. 139-140.]

19. CATEURA (2), pp. 296-298.

20. TORRES, ANTONIO DE LA: Documentos sobre relaciones internacionales de los Reyes Católicos. Biblioteca Reyes Católicos. CSIC. Barcelona, 1965. Vol. III. pp. 290-291.

21. Ibídem. Vol. V. pp. 340-341. Vol. VI, pp. 258-259.

22. Ibídem. Vol. VI, pp. 333-335.

23. En 1452 figura entre los maestres de naves pertenecientes a Alfonso el Magnánimo, un Bernat de Pachs. (RYDER, ALAN: El reino de Nápoles en la época de Alfonso el Magnánimo. Edicions Alfons el Magnànim, Valencia. 1987. p. 359.) 24. TORRES (20), Vol. III, p. 398. El 14 de mayo de 1491, Bonifacio fue nombrado Cónsul de Venecianos en Mallorca por el Capitán de las galeras del Dux de Venecia en Flandes, estante en Mallorca, Nicolás Contareno. (Ibídem, p. 403,513 .) Bonifacio ejercía el oficio desde hacía más de veintisiete años, pero un Pedro Dotto -alegando estar el consulado vacante- consiguió ser nombrado por el Dux aunque no obtuvo la provisión del Rey de Aragón por haber habido falsedad. Es entonces cuando Contareno, quien tenía autoridad ducal, reconoció a Pachs en el oficio. También se conserva la confirmación del nombramiento hecha por don Fernando el 21 de julio de 1491, en que se mencionan los servicios de su abuelo Nicolás y de su padre Arnaldo en el dicho oficio. (lbídem. pp. 423-425, 513.) 
25. CATEURA (2), pp. 295-296.

26. Ibídem.

27. RUIZ POVEDANO, JOSE MARIA: El primer gobierno municipal de Málaga (1489-1495). Universidad de Granada - Ayuntamiento de Málaga. Granada, 1991. pp. 99-104. PRIETO, AMALIA y ALVAREZ, CONCEPCION: Catálogo del Registro General del Sello. Vol. VIII,(enero-diciembre 1491). Archivo General de Simancas, Valladolid. 1963. p. 1076. Soy de parecer que el Consulado General sí pretendía instaurar una jurisdicción especial, a pesar que se haya sostenido la opinión contraria en base a una puntuación moderna en la prueba documental principal. No olvidemos que se trataba de un consulado general de extranjeros.

28. BASAS FERNANDEZ, MANUEL: El consulado de Burgos en el siglo XVI. Diputación Provincial de Burgos, 1994. p. 35.

29. RAMIREZ, JUAN: Libro de las Bulas y Pragmáticas de los Reyes Católicos. Prefacio por don Alfonso García-Gallo y don Miguel Angel Pérez de la Canal. Instituto de España, Madrid. 1973. t.II, pp. CCCXXIr-CCCXXIv.

30. Cortes de los antiguos Reinos... (18), pp. 122. Ejemplo de lo dicho es la Ley 39 del Ordenamiento: "Por la malicia e ignorancia de los abogados suelen las partes litigantes muchas veces rescebir danno, e para rremediar esto ansy por derecho como por las leyes [de nuestros reynos] fue estatuido quelos abogados jurassen en manos de un juez que bien e fielmente vsarian del officio de abogazia e consejarian justamente a sus partes, e no ayudarian a causa injusta, e luego que conosciesen que su parte no traya justicia, dexarian la causa. E porque la disposicion de las dichas leyes avn no abasta para refrenar las malicias delos caluniosos abogados, queriendo remediar en esto, hordenamos e mandamos quelas dichas leyes e hordenanzas sean guardadas de aqui adelante, e que los jueces, asy de la nuestra Corte como delas cibdades e villas e logares de nuestros reynos, sean solycitos en recibyr delos abogados los tales juaramentos e esto baste para exsaminacion dellos, non enbargante que por nos fue mandado en la cibdad de Cordoua quelos del nuestro Consejo exsaminassen los abogados dela Corte. Es si acaesciese que por negligencia e inpericia del abogado, que se puede colegir de los abtos del proceso, la parte a quien ayudase perdiese su derecho, mandamos que el tal abogado sea tenudo de pagar a su parte el danno que por esto le viniere con las costas, el qual juez o juezes ante quien se viere el tal pleyto lo faga luego pagar ayn dilacion alguna: e porque podria acaecer quel abogado por ayudar a su parte tentase de fatigar injustamente a la otra parte, mandamos que cada e quando el juez dela causa o qual quier delas partes pidiere, quel abogado dela otra parte jure en qual quier parte del pleyto non ayudará ni favorecerá en aquella causa a su parte injustamente nin contra derecho a sabyendas, e que cada e quando conosciere la injusticia de su parte gela notificará e non le ayudará dende en adelante, e que este tal abogado sea tenudo de fazer e faga luego el tal juramento, so pena que, si escusacion enello posiere o non lo fiziere, por el mismo fecho finque e sea inhabile para 
exercer el officio de auogazia e dende en adelante non vse del dicho officio, so las penas que le fueren puestas sobre ello por el dicho juez."

31. La ley 46 de las Cortes de Toledo de 1480 está dedicada a poner remedio a la dilación en el pago de deudas, remitiéndose a una Pragmática del rey Enrique III de Castilla, de fecha del 20 de mayo de 1396. El rey don Enrique a petición de los Cónsules de Génova en Sevilla, quienes se quejaron que ellos comerciaban con cristianos, moros y judíos y que tenían dificultades de cobrar sus mercadurías. Las alegaciones para el impago de las deudas eran muy variadas tanto desde un pacto previo o pago de las dichas, "e alegan otras excepciones, de que dicen que tienen los testigos en otros reynos e en lerusalen, non seyendo las pagas o excepciones puestas verdaderas, por la qual razon se aluengan los pleytos e les fazen fazer grandes costas e espensas... " Los Reyes, en 1480 decidieron que la vieja pragmática fuera guardada por ley general en todos sus reinos al todavía subsistir las mismas circunstancias que la habían causado y que "esso mismo aya lugar la disposicion desta ley en la deuda que se deuiesse por sentencia pasada en cosa juzgada e que el termino a que ha de mostrar la paga al que allega, que dice la prematica sea luego, que se entienda en diez dias e que en todas las clausulas quede por ley general la dicha prematica con las condiciones susodichas..." (pp. 128-130).

32. GARCIA SANZ, ARCADIO: La influencia de los consulados de mar de Barcelona y Valencia en la erección del consulado de Burgos. Boletín de la Sociedad Castellonense de Cultura. Castellón, 1969. Tomo XLV, pp. 237, 239. 33. RUIZ (27), p. 104.

34. La doctora Ferreira recoge dos menciones, una en un documento relativo a un Consulado de Castellanos de 1498 en que se mencionan "iuxta capitula et ordinationes consulatus officii", y en otro de un Consulado de españoles de 1488 unos "capitula ipsius Consulatus offici". Según la investigadora se trataría de unas ordenanzas específicas, distintas a las contenidas en el Ordenamiento de Montalvo sobre la función judicial general que todavía son inéditas. Sin contradecir tal opinión, propongo la posibilidad que fueran privativas de cada consulado, y aunque específicas y diferenciadas su contenido sería parecido. Tales capítulos no serían textos extensos. [FERREIRA (4), p. 197.]

35. Ibídem. pp. 199, 211-212, 224.

36. CATEURA (2), pp. 295, 298.

37. SMITH, ROBERT SIDNEY: Historia de los Consulados de Mar (12501700). Ediciones Península, Barcelona. 1978, pp. 33-34.

38. GARCIA (32), pp. 235-236.

39. RAMIREZ (29), T. II, p. CCCXIXv.

40. Cortes de los antiguos Reinos... (18), pp. 185-186.

41. CORONAS, GONZALEZ, SANTOS M.: Derecho mercantil castellano. Dos estudios históricos. Colegio Universitario de León, 1979. p. 43. 


\section{APÉNDICE DOCUMENTAL}

[AGS, RGS. 1485 - XI, 14]

Bartolome de Melgar /

Merçed del ofiçio de consul de castellanos de la çibdad / e Reyno de Mallorcas. 1

\section{A / \\ $+1$}

Don Fernando e doña Ysabel etc. A vos los Visorrey e Governador( ${ }^{*}$ s) / e otras justyçias qualesquier de la nuestra ( ${ }^{*}$ Abdiençia) çibdad e Reyno / de Mallorcas e a qualesquier capitanes e patrones e mercaderes nuestros / vasallos, subditos e naturales a quien lo contenido en esta nuestra / Carta toca e atañe en qualquier manera e por qualquier rrason / que sea e a cada vno de vos a quien esta nuestra Carta sea mostrada / o el traslado della sygnado de escriuano publico, salud e graçia. Sepades / que por parte de Bartolome de Melgar fijo de Bartolome de Melgar / nuestro Consul de la naçion de los castellanos de la dicha çibdad e / Reyno de Mallorcas Nos fue fecha rrelaçion diziendo quel señor / Rey don Enrrique nuestro hermano cuya anima Dios aya ovo fecho e fiso / merçed al dicho Bartolome de Melgar su padre del dicho ofiçio de / Consulado de todos los nuestros Reynos e señorios de Aragon / e Seçilia con facultad que lo pudiese rrenunçiar en qualquier persona / quel quisiese e por bien touiese por virtud de la qual dicha merçed el dicho / Bartolome de Melgar su padre fue Consul de la dicha naçion / en su vida e que despues rrenunçio el dicho ofiçio en el dicho Bartolome / de Melgar su fijo e fue confirmada la dicha rrenunçiaçion que del / fue fecha por el señor Rey don Enrrique e le fue fecha nueva / merçed del dicho ofiçio de Consulado al dicho Bartolome de Melgar / e despues Nos al tiempo que çuçedimos e rreynamos en estos nuestros / Reynos confirmamos la dicha merçed e le dimos facultad para / que la pudiese rrenunçiar en vn fijo suyo quando quisiese e / por bien touiese por virtud de las quales dichas rrenunaçiones / [FV.] dichas merçedes e confirmaçiones. E la ha vsado el dicho ofiçio e lleuado / los derechos e salarios a el anexas e pertesçientes e que despues / con rrelaçion falsa e no fasiendo mençion como el tenia el dicho / ofiçio e le avia seydo fecha merçed del Nos fezimos merçed del dicho / ofiçio de Consulado a Martin de Portugalete [F.2] dichas merçedes e la dicha carta de merçed quel dicho Martin de Portogalete gano fue / con rrelaçion no verdadera touimoslo por bien e por la presente de/claramos la dicha merçed fecha al dicho Martin de Portogalete ser / ninguna e de ningund valor e efetto como ganada con rrelaçion / no verdadera e subrretyçia e que la no podiamos ni deuia/mos dar 
en su perjuysio, porque vos mandamos / que syn enbargo de la dicha merçed fecha al dicho Martin / de Portogalete ayays e tengays al dicho Bartolome / de Melgar por nuestro Consul de los mercaderes e / otras personas destos nuestros Reynos de Castilla / e de Leon en la dicha çibdad e Reyno de Ma/ llorcas e le dexeys e consyntays gozar del dicho ofiçio / e lo vsar e exerçer segund que fasta aqui lo han fecho e / puede e deue faser como nuestro Consul de la dicha çibdad / e Reyno e gozar de las honrras, gracias, franquezas, libertades / e esençiones que por rrason del dicho ofiçio puede e deue gozar / e çerca de la prouision del dicho ofiçio se guarde la ley por Nos / fecha en las Cortes de Toledo. E los vnos ni los otros etc. so pena / de priuaçion de los ofiçios e confiscaçion de los bienes etc. con priuilegio e/tc. Dada en la villa de Alcala de Henares a veynte e dos dias / de novienbre Año del Señor de de mill e quatroçientos e ochenta / e çinco años. Yo el Rey. Yo la Reyna. Yo Felipe Clemeinte Proto/notario e Secretario del Rey e Reyna nuestros señores, la / fize escreuir por su mandado en forma justa Andres dotor. /

NOTA DEL AUTOR: En el reverso del folio existe la siguiente anotación compuesta por cuatro líneas, tres de las cuales tachadas, que corresponden a otro registro: "Badajoz e Trugillo e Merida (de Caçeres e Alburquer e (*Villena) e Areualo. ( Diego Arroyal fijo de Diego Aluares Sepeda... )."

NORMAS DE PUNTUACION: 1. Las palabras tachadas se reproducen entre paréntesis. 2. Se mantiene la ortografía original excepción de los nombres propios e institucionales que se escriben con mayúsculas. 